\title{
PENERAPAN PERHITUNGAN PAJAK PENGHASILAN (PPH) PASAL 21 PEGAWAI TETAP PADA PT. BUMI MITRA BUTON ABADI
}

\author{
Ernawati Malik \\ Program Studi Akuntansi, Fakultas Ekonomi \\ Universitas Muhammadiyah Buton, Baubau, Indonesia \\ e-mail:ernamalik8975@gmail.com
}

\begin{abstract}
ABSTRAK
Penelitian ini bertujuan untuk mengetahui laporan Pajak Terhutang dan pemotongan pajak atas pegawai tetap PT. Bumi Mitra Buton Abadi sesuai dengan ketentuan Undang-Undang Perpajakan No. 36 Tahun 2008.Metode penelitian yang digunakan adalah metode analisis deskriptif.

Hasil penelitian menunjukan bahwa pemotongan pajak penghasilan atas pegawai tetap dan laporan pajak terhutang pada PT. Bumi Mitra Buton Abadi belum sesuai dengan ketentuan Undang-Undang Perpajakan No. 36 Tahun 2008 karena adanya selisih pembayaran sebesar Rp. 200.000,00. Selisih pembayaran tersebut disebabkan oleh perbedaan penggunaan dasar Penghasilan Tidak Kena Pajak (PTKP). Dasar PTKP yang digunakan oleh PT. Bumi Mitra Buton Abadi masih mengacu pada peraturan lama dengan nilai PTKP sebesar Rp. 48.000.000,00 sedangkan perhitungan menurut Undang-Undang Perpajakan No. 36 Tahun 2008 sebesar Rp. 72.000.000,00. Dengan adanya selisih pembayaran maka PT. Bumi Mitra Buton Abadi harus melakukan pembetulan pada tahun 2017.
\end{abstract}

Kata kunci : Pemotongan Pajak, Perhitungan Pajak, PPh Pasal 21

\begin{abstract}
This study aims to determine the tax payable report and withholding tax on permanent employees of PT. Bumi Buton Abadi Partners in accordance with the provisions of the Taxation Law No. 36 of 2008. The research method used is descriptive analysis method.

The results of the study show that the deduction of income tax on permanent employees and tax returns is payable to PT. Bumi Mitra Buton Abadi has not been in accordance with the provisions of the Taxation Law No. 36 of 2008 due to a payment difference of Rp. 200,000.00. The payment difference is caused by differences in the use of the basis of Non-Taxable Income (PTKP). The PTKP basis used by PT. Bumi Mitra Buton Abadi still refers to the old regulations with a PTKP value of Rp. 48,000,000.00 while the calculation under the Taxation Law No. 36 of 2008 amounting to Rp. 72,000,000.00. With the payment difference, PT. Bumi Mitra Buton Abadi must make corrections in 2017.
\end{abstract}

Keywords: Tax Withholding, Tax Calculation, Article 21 Income Tax 


\section{PENDAHULUAN}

Pajak merupakan salah satu kewajiban yang harus dipenuhi oleh setiap warga negaradalam rangka pembiayaan negara dan pembangunan nasional [1]. Sistem perpajakan yang digunakan di Indonesia adalah with holding system. With holding system adalah suatu cara pemungutan pajak yang perhitungan besarnya pajak yang terutang oleh wajib pajak dilakukan oleh pihak ketiga [2]. Pihak ketiga yang dimaksud dalam system ini adalah wajib pajak badan. Badan usaha yang bertindak sebagai pemberi kerja, setelah memenuhi persyaratan tertentu yang diwajibkan, pada umumnya akan disebut sebagai pihak yang ditunjuk untuk melakukan pemotongan pajak [3].

Salah satu jenis pajak penghasilan yang menggunakan with holding system adalah Pajak Penghasilan (PPh) Pasal 21. PPh Pasal 21 merupakan pajak yang terutang atas penghasilan yang menjadi kewajiban wajib pajak untuk membayarnya.Penghasilan yang dimaksud adalah berupa gaji, honorarium, tunjangan dan pembayaran lain dengan nama apapun sehubungan dengan pekerjaan, jasa, atau kegiatan yang dilakukan oleh wajib pajak orang pribadi dalam negeri [4]. Pajak penghasilan Pasal 21 ini terutang pada akhir bulan dilakukannya pembayaran atau pada akhir bulan terutangnya penghasilan yang bersangkutan [5].

Subjek PPh Pasal 21 adalah karyawan/pegawai yang terdiri dari pegawai tetap, pegawai lepas, penerima pensiun, penerima honorarium, penerima upah, dan orang pribadi lainnya yang menerima atau memperoleh penghasilan sehubungan dengan pekerjaan, jasa, dan kegiatan dari pemotong pajak [6]. Pemotong PPh Pasal 21 adalah setiap orang pribadi atau badan yang diwajibkan oleh undang-undang untuk memotong pajak penghasilan Pasal 21. Pihak yang wajib melakukan pemotongan, penyetoran, dan pelaporan pajak penghasilan Pasal 21 adalah pemberi kerja, bendaharawan pemerintah, dana pensiun, badan, perusahaan dan penyelenggara kegiatan [7]. Sedangkan objek PPh Pasal 21 adalah penghasilan yang dipotong oleh pemotong pajak untuk dikenakan pajak penghasilan Pasal 21 yang terdiri dari penghasilan yang diterima atau diperoleh secara teratur, penghasilan yang diterima atau diperoleh secara tidak teratur, upah harian, upah mingguan, upah satuan, upah borongan, uang pesangon dan pembayaran lain yang sejenis, pembayaran lain sebagai imbalan sehubungan dengan pekerjaan, jasa, dan kegiatan yang dilakukan 
oleh wajib pajak dalam negeri, dan penerimaan dalam bentuk natura atau kenikmatan lainnya [4].

Dalam perhitungan PPh Pasal 21 yang terutang digunakan tarif pajak. Tarif pajak adalah tarif untuk menghitung besarnya pajak yang terutang atau pajak yang harus dibayar. Besarnya tarif pajak dapat dinyatakan dalam persentase. Tarif pajak yang digunakan adalah tarif PPh Pasal 17 [4].

PT. Bumi Mitra Buton Abadi merupakan salah satu perusahaan swasta yang bergerak dalam bidang pengolahan aspal. Sebagai sebuah perusahaan yang didirikan dan beroperasi di Indonesia, perusahaan ini tidak lepas dari kewajibannya untuk membayar pajak yang telah ditentukan, termasuk pembayaran pajak penghasilannya. Penelitian akan fokus pada penerapan perhitungan PPh Pasal 21 pegawai tetap PT. Bumi Mitra Buton Abadi.

\section{METODE PENELITIAN}

Populasi adalah keseluruhan jumlah yang terdiri atas obyek atau subyek yang mempunyai karakteristik dan kualitas tertentu yang ditetapkan oleh peneliti dan kemudian ditarik kesimpulan [8].Populasi dalam penelitian ini adalah gaji pegawai tetap PT. Bumi Mitra Buton Abadi.

Sampel adalah sebagian dari subyek dalam populasi yang diteliti, yang sudah tentu mampu secara representatif dapat mewakili populasinya [9].Sampel dalam penelitian ini adalah gaji pegawai tetap PT. Bumi Mitra Buton Abadi tahun 2016.

Data yang akan digunakan untuk menghitung PPh Pasal 21 atas penghasilan pegawai tetap merupakan data kuantitatif dan data kualitatif. Data kuantitatif yaitu data dalam bentuk angka-angka yang memiliki keterkaitan dengan obyek yang diteliti.Data tersebut meliputi jumlah dan data gaji pegawai tetap PT. Bumi Mitra Buton Abadi tahun 2016.

Data kualitatif yaitu data yang berupa penjelasan yang dijadikan bahan analisis sebagai obyek penelitian.Data tersebut meliputi keterangan susunan keluarga, penjabaran struktur organisasi, kebijakan pengajian.Data-data tersebut diperoleh secara langsung dari pemilik perusahaan.

Sumber data yang digunakan dalam penelitian ialah data primer dan data sekunder.Data primer yaitu data yang diperoleh secara langsung dari perusahaan dengan mengadakan wawancara dan pengamatan secara langsung dengan aparatur dan 
pegawai yang berhubungan dengan masalah yang dibahas.Data sekunder yaitu data yang pengumpulannya diperoleh dari buku-buku yang digunakan sebagai bahan acuan yang diperoleh dari berbagai sumber yang memiliki hubungan dengan penelitian ini berupa daftar gaji pegawai dan sejarah perusahaan PT. Bumi Mitra Buton Abadi.

Adapun teknik pengumpulan data dalam penelitian ini adalah wawancara, dokumentasi, dan studi pustaka. Wawancara, yaitu teknik pengumpulan data dengan mengadakan tanya jawab secara langsung dengan pimpinan dan orang-orang yang berwenang dalam PT. Bumi Mitra Buton Abadi. Dokumentasi, yaitu teknik pengumpulan data dengan cara melihat dan menggunakan laporan-laporan, catatan-catatan, maupun formulir-formulir yang terdapat dalam perusahaan. Studi pustaka yaitu pengumpulan data yang bersumber dari literatur, internet, aplikasi tax base, atau hasil penelitian terdahulu yang diperoleh dari perpustakaan yang berkaitan dengan masalah dalam penelitian ini.

Metode analisis data yang digunakan untuk membahas penelitian ini adalah metode analisis deskriptif, yaitu suatu metode pembahasan permasalahan yang sifatnya menguraikan, menggambarkan suatu keadaan atau data serta melukiskan dan menerapkan suatu keadaan sedemikian rupa sehingga dapat ditarik kesimpulan. Berikut ini langkah-langkah analisis data penelitian ini.

1. Mengumpulkan dan mengolah data serta informasi berupa data penghasilan karyawan, daftar susunan keluarga, informasi kebijakan perusahaan tentang pemberian gaji.

2. Menentukan Penghasilan Tidak Kena Pajak (PTKP) berdasarkan susunan daftar keluarga karyawan.

3. Menghitung PPh Pasal 21 bulanan untuk pegawai tetap yang terutang dengan cara, gaji bersih dikurangi dengan biaya jabatan dan PTKP kemudian dikalikan tarif PPh Pasal 21 [4].

\section{HASIL DAN PEMBAHASAN}

\section{a. Hasil Penelitian}

Berdasarkan wawancara dengan pimpinan dan orang-orang yang berwenang dalam PT. Bumi Mitra Buton Abadi pada tanggal 12 Agustus 2017 dapat diketahui bahwa PT. Bumi Mitra Buton Abadi bertindak sebagai pemotong pajak PPh Pasal 21 karyawan. Sebab berdasarkan definisi pemotong pajak yang berbunyi setiap 
orang pribadi atau badan yang diwajibkan oleh undang-undang untuk memotong pajak penghasilan pasal 21. Pihak yang wajib melakukan pemotongan, penyetoran dan pelaporan pajak penghasilan Pasal 21 adalah pemberi kerja, bendaharawan pemerintah, dana pensiun, badan, perusahaan dan penyelenggara kegiatan. Oleh sebabitu, PT. Bumi Mitra Buton Abadi digolongkan sebagai pemotong pajak PPh Pasal 21 karyawan. Dalam penelitian ini PT. Bumi Mitra Buton Abadi sudah melakukan kewajibannya menyetor PPh badan dan sudah menghitung PPh Pasal 21 karyawan tetap yang terutang.

PT. Bumi Mitra Buton Abadi yang bergerak dalam bidang pengolahan aspal memiliki 24orang karyawan tetap yang setiap bulannya memperoleh gaji pokok dan tambahan lain seperti uang lembur. Digolongkan sebagai pegawai tetap karena tidak ada sistem kontrak per tahun yang harus diperpanjang kembali apabila habis masa kontrak.

Pengolongan karyawan sebagai pegawai tetap oleh perusahaan dianggap sudah tepat oleh penulis karena sudah sesuai dengan kriteria-kriteria pegawai tetap menurut undang-undang ketenagakerjaan yang berbunyi, Pegawai tetap yaitu orang pribadi yang bekerja pada pemberi kerja yang menerima atau memperoleh gaji dalam jumlah tertentu secara berkala, termasuk anggota dewan komisaris dan anggota dewan pengawas yang secara teratur terus -menerus ikut mengelola kegiatan perusahaan secara langsung. Berikut daftar gaji karyawan PT. Bumi Mitra Buton Abadi.

\section{b. Pembahasan}

Jumlah pegawai tetap PT. Bumi Mitra Buton Abadi sebanyak 24 orang. Pegawai tetap yang mempunyai Penghasilan Kena Pajak (PKP) sebanyak 2 orang karena penghasilannya melebihi Penghasilan Tidak Kena Pajak (PTKP) sebesar Rp. 4.500.000,- per bulan. Sedangkan pegawai tetap yang penghasilannya dibawah Penghasilan Tidak Kena Pajak (PTKP) sebanyak 22 Orang.

Perhitungan PPh Pasal 21 bulanan seluruh pegawai tetap PT. Bumi Mitra Buton Abadi yang terutang didapat dengan mengalikan penghasilan per bulan dengan 12 bulan sehingga diperoleh penghasilan bruto.

Setelah didapat penghasilan bruto, khusus untuk pegawai tetap diberikan pengurang berupa biaya jabatan sebesar5\% dari penghasilan bruto yang maksimal dapat dikurangkan sebesar Rp.500.000 perbulan atau sebesar Rp.6.000.000 per tahun. 
Atas pengurangan ini diperoleh penghasilan netto yang nantinya dikurangkan lagi dengan PTKP (Penghasilan Tidak Kena Pajak). PTKP untuk karyawan status PTKP nya ditetapkan adalah K/3. Dari pengurangan tersebut menghasilkan PKP (Penghasilan Kena Pajak) yang nantinya diberlakukan tarif PPh Pasal 17. Sehingga diperoleh PPh 21 terutang selama setahun. Sedangkan untuk memperoleh PPh 21 sebulan, PPh 21 terutang selama setahun dibagi kembali dengan 12 bulan.

Perbandingan prosedur penghitungan dan pemotongan Pajak Penghasilan Pasal 21 pada PT. Bumi Mitra Buton Abadi dengan prosedur penghitungan dan pemotongan berdasarkan ketentuan Undang-Undang No. 36 Tahun 2008 tentang Pajak Penghasilan adalah sebagai berikut.

1. Tarif pajak yang diterapkan pada PT. Bumi Mitra Buton Abadi atas Penghasilan Kena Pajak (PKP) telah sesuai dengan Undang Undang No. 36 Tahun 2008.

2. Besarnya Penghasilan Tidak Kena Pajak (PTKP) yang dikenakan sesuai dengan ketentuan Undang Undang No. 36 Tahun 2008 dan [10].

3. Biaya jabatan yang dikenakan PT. Bumi Mitra Buton Abadi besarnya 5\% dari penghasilan bruto.

4. Penghitungan pajak penghasilan PPhPasal21 PT. Bumi Mitra Buton Abadi dan perbandingannya dengan Undang-Undang Perpajakan No. 36 Tahun 2008. Berikut ini perhitungan pemotongan Pajak Penghasilan (PPh) Pasal 21 terhadap penghasilan karyawan tetap dan membandingkannya dengan menggunakan perhitungan menurut PT. Bumi Mitra Buton Abadi.

Pegawai tetap dengan nama Tonni Lim Putra memiliki 3 orang anak memperoleh penghasilan Rp.8.000.000 perbulan.Maka besarnya PPh 21 Tonni Lim Putra yang terutang adalah sebagai berikut:

\section{Perhitungan Menurut Perusahaan}

Nama Karyawan : Tonni Lim Putra

Status $: \mathrm{K} / 3$

Gaji Pokok 8.000.000

Pengurangan

Biaya Jabatan: 5\% x 8.000.000 $=400.000$

Penghasilan neto (bersih) sebulan

$7.600 .000,00$ 
PPh Terutang (lihatTarif PPh Pasal 21): 5\% x 43.200.000=2.160.000

PPh Pasal 21 sebulan: $2.160 .000 / 12=$ Rp. 180.000

$180.000,00$

Perhitungan Menurut Peraturan Undang-Undang Perpajakan No. 36 Tahun 2008

Nama Karyawan : Tonni Lim Putra

Status $\quad: \mathrm{K} / 3$

Gaji Pokok

$8.000 .000,00$

Pengurangan

Biaya Jabatan: $5 \%$ x 8.000.000=

$400.000,00$

Penghasilan neto (bersih) sebulan

$7.600 .000,00$

Penghasilan neto setahun $12 \times 7.600 .000$

$91.200 .000,00$

Penghasilan Tidak Kena Pajak (PTKP)

Penghasilan Kena Pajak Setahun

19.200.000,00

PPh Terutang (lihat Tarif PPh Pasal 21): 5\% x 19.200.000=960.000

PPh Pasal 21 sebulan: 960.000/12 = Rp.80.000

$80.000,00$

Jadi, perhitungan PPh Pasal21 Tonni Lim Putra yang terutang perbulan berbeda dengan perusahaan dan Undang-Undang Perpajakan No. 36 Tahun 2008. Menurut perhitungan perusahaan pajak terhutang sebesar Rp. 180.000,00 dan perhitungan menurut Undang-Undang sebesar Rp.80.000,00.

Penyebab perbedaan perhitungan pajak antara perusahaan dengan UU Nomor 36 karena pada tahun 2016 PT. Bumi Mitra Buton Abadi masih menggunakan dasar Penghasilan Tidak Kena Pajak (PTKP) lama yaitu sebesar Rp. 48.000.000. Hal ini disebabkan oleh PT. Bumi Mitra Buton Abadi belum memperbaharui informasi peraturan perpajakan yang berlaku. Untuk itu agar terhindar dari kesalahan di tahun 2016, PT. Bumi Mitra Buton Abadi sekarang telah menggunakan aplikasi tax base untuk mendapatkan informasi perpajakan terbaru. 


\section{Perhitungan Kurang Bayar/Lebih Bayar PPh Pasal 21.}

Jumlah PPh 21 kurang bayar/lebih bayar karyawan per bulan didapat dari perbandingan perhitungan menurut perusahaan dan menurut UU No. 36 Tahun 2008. Dari hasil analisis perhitungan dapat dilihat bahwa ada selisih untuk PPh Pasal 21 yang disetor yaitu selisih lebih bayar. Selisih lebih bayar tersebut disebabkan oleh perhitungan menurut perusahaan pajak terhutang sebesar Rp. 336.250,00 dan perhitungan menurut Undang-Undang Perpajakan No. 36 Tahun 2008 sebesar Rp. 136.250,00. Karena adanya selisih bayar tersebut maka pada bulan Agustus 2017 PT. Bumi Mitra Buton Abadi melakukan Pembetulan Ke 1 atas kelebihan bayar PPh Pasal 21 pada tahun 2016.

\section{KESIMPULAN}

Berdasarkan hasil analisis data dan pembahasan mengenai dapat disimpulkan bahwa pemotongan pajak penghasilan atas pegawai tetap dan laporan pajak terhutang pada PT. Bumi Mitra Buton Abadi belum sesuai dengan ketentuan Undang-Undang Perpajakan No. 36 Tahun 2008 karena adanya selisih pembayaran sebesar Rp. 200.000,00. Selisih pembayaran tersebut disebabkan oleh perbedaan penggunaan dasar Penghasilan Tidak Kena Pajak (PTKP). Dasar PTKP yang digunakan oleh PT. Bumi Mitra Buton Abadi masih mengacu pada peraturan lama dengan nilai PTKP sebesar Rp. 48.000.000,00 sedangkan perhitungan menurut Undang-Undang Perpajakan No. 36 Tahun 2008 sebesar Rp. 72.000.000,00. Dengan adanya selisih pembayaran maka PT. Bumi Mitra Buton Abadi harus melakukan pembetulan pada tahun 2017.

\section{SARAN}

Berikut ini saran yang dimaksudkan untuk dapat memberikan manfaat kepada pihakpihak yang membutuhkan. PT. Bumi Mitra Buton Abadi lebih terus mempertahankan dan meningkatkan kepatuhan terhadap Peraturan Perpajakan guna menghindari masalah serta pelanggaran-pelanggaran dan tetap mengamati informasi-informasi terbaru yang diberlakukan oleh Direktorat Jenderal Pajak.PT. Bumi Mitra Buton Abadi khususnya bagian keuangan akan jauh lebih baik jika melampirkan cara perhitungan pajak beserta contohnya pada slip gaji karyawan, agar karyawan bisa mengerti cara perhitungan pajaknya.Bagi para pembaca dapat dijadikan tambahan pengetahuan khususnya pada jurusan perpajakan. 


\section{DAFTAR PUSTAKA}

[1] Oe, Melta Johan. 2010. Pajak sebagai Penunjang Pembangunan Nasional di Indonesia. Jurnal Pranata Hukum, Volume 5, Nomor 2.

[2] Devano, Sony dan Siti Kurnia R. 2006. Konsep Perpajakkan, Teori dan Isu. Jakarta: Kencana Predana Media Group.

[3] Sumarsan, Thomas. 2012. Perpajakan Indonesia: Pedoman Perpajakan yang Lengkap Berdasarkan Undang-Undang Terbaru. Jakarta: PT Indeks.

[4] Republik Indonesia. Undang Undang Nomor 36 Tahun 2008 Tentang Pajak Penghasilan.

[5] Lubis, Irwansyah, Gustian Djuanda, dan Ardiansyah Lubis. 2009. Review Pajak, Orang Pribadi dan OrangAsing, Jakarta: Salemba Empat

[6] Peraturan Direktur Jendral Pajak Nomor: 15/PJ/2006 Tentang Objek Pajak Penghasilan Pasal 21

[7] Peraturan Direktur Jendral Pajak Nomor: PER - 16/PJ/2016 tentang pemotongan, penyetoran, dan pelaporan pajak atas penghasilan sehubungan dengan pekerjaan, jasa, dan kegiatan orang pribadi.

[8] Wiratna. 2014. Metodologi Penelitian. Yogyakarta: Pustaka Baru Press.

[9] Rutoto, Sabar. 2007. Pengantar Metedologi Penelitian. FKIP: Universitas Muria Kudus.

[10] Peraturan perundang-undangan Nomor: 101-PMK.010-2016 tentang Penyesuaian Besarnya Penghasilan Tidak Kena Pajak 